\title{
Myosin Va Controls Oligodendrocyte Morphogenesis and Myelination
}

\author{
Jacob A. Sloane and Timothy K. Vartanian \\ Department of Neurology, Beth Israel Deaconess Medical Center, Harvard Institutes of Medicine, Boston, Massachusetts 02215
}

A product of myosin Va mutations, Griscelli's syndrome type 1 (GS1) is characterized by several neurologic deficits including quadraparesis, mental retardation, and seizures. Although multiple studies have not clearly established a cause for the neurologic deficits linked with GS1, a few reports suggest that GS1 is associated with abnormal myelination, which could cause the neurologic deficits seen with GS1. In this report, we investigate whether myosin Va is critical to oligodendrocyte morphology and to myelination in vivo. We found that myosin Va-null mice exhibit significantly impaired myelination of the brain, optic nerve, and spinal cord. Oligodendrocytes express myosin Va and loss of myosin Va function resulted in significantly smaller lamellas and decreased process number, length, and branching of oligodendrocytes. Loss of myosin Va function also blocked distal localization of vesicle-associated membrane protein 2 (VAMP2), which is known to associate with myosin Va. When VAMP2 function was disrupted, oligodendrocytes exhibited similar morphologic deficits to what is seen with functional ablation of myosin Va. Our findings establish a role for both myosin Va and VAMP2 in oligodendrocyte function as it relates to myelination.

Key words: oligodendrocyte; myelin; myosin Va; VAMP2; synaptobrevin-2; Griscelli’s syndrome

\section{Introduction}

Defects in myelin contribute to poor neurologic outcomes in multiple sclerosis and several developmental disorders. Griscelli's syndrome type 1 (GS1), a developmental disorder resulting from a mutation to the myosin Va heavy chain and characterized by severe neurologic deficits, including hypotonia, quadraparesis, marked motor developmental delay, mental retardation, seizures, and ataxia (Pastural et al., 1997; Ivanovich et al., 2001; Anikster et al., 2002; Sanal et al., 2002; Bahadoran et al., 2003), may be a product of impaired myelination (Kelton and Rauch, 1962; Winterbourn et al., 1971; Noguchi et al., 1983; Pastural et al., 1997; Anikster et al., 2002). In this report, we test whether myosin Va loss of function impairs oligodendrocyte morphogenesis and myelination in a GS1 mouse model, dilute-lethal, which possesses a myosin Va-null mutation (Mercer et al., 1991).

Although it is possible that abnormal myelination accounts for neurologic symptoms of myosin Va-null mice, it is clear that neuronal function is not uniformly or severely impaired in myosin Va-null mice, despite diffuse expression of myosin Va (Rodriguez and Cheney, 2002; Zhu et al., 2005). For example, long-term depression is impaired in myosin Va-null cerebellar Purkinje neurons (Miyata et al., 2000), but not hippocampal CA1 neurons (Schnell and Nicoll, 2001). Myosin Va-null DRG neurons exhibit

\footnotetext{
Received May 22, 2007; revised Aug. 13, 2007; accepted Aug. 15, 2007.

This work was supported by National Multiple Sclerosis Society Grant FG1623A1 (J.A.S.) and National Institutes of Health Grants NS038475 and NSO42317 (T.K.V.). We thank Yingha Ma, Bela Kosaris, and Cynthia Hayne for help on research design and editing.

Correspondence should be addressed to Timothy K. Vartanian, Department of Neurology, Beth Israel Deaconess Medical Center, Harvard Institutes of Medicine, Room 836, 77 Louis Pasteur Avenue, Boston, MA 02215. E-mail: tvartani@caregroup.harvard.edu.

DOI:10.1523/JNEUROSCI.2326-07.2007

Copyright $\odot 2007$ Society for Neuroscience $\quad 0270-6474 / 07 / 2711366-10 \$ 15.00 / 0$
}

impaired anterograde synaptic vesicle movement (Bridgman, 1999), but synaptic vesicle mobilization and postsynaptic responses are normal in hippocampal CA1 neurons (Schnell and Nicoll, 2001). In addition, neuronal growth cone size, and filopodia morphology, are not significantly affected in myosin Va-null cortical neurons, despite neuronal growth cone localization of myosin Va (Evans et al., 1997). Although others showed that myosin $\mathrm{V}$ is important for filopodial extension in DRG neuron growth cones (Wang et al., 1996), the techniques used ablated function of all myosin $\mathrm{V}$ isoforms (i.e., myosin $\mathrm{Va}, \mathrm{Vb}$, and $\mathrm{Vc}$ ), and their finding has not been confirmed independently (Evans et al., 1997). Therefore, myosin Va dysfunction in neurons, including changes in synaptic vesicle movement or in neuronal morphology, is either too modest to affect function and/or growth of a majority of neuronal subtypes or functional redundancy of myosins in neurons prevents more severe cellular effects.

Loss of myosin Va function in glia may be another way to account for GS1 neurologic deficits. Specifically, aberrant myelination by oligodendrocytes may be a significant CNS pathology associated with GS1. GS1 patients exhibit diffuse white matter and cerebellar atrophy by imaging (Duran-McKinster et al., 1999). In addition, brains of myosin Va-null mice exhibit a prominent delay in CNS myelination (Kelton and Rauch, 1962; Winterbourn et al., 1971), deficits in myelin-associated lipids, including cerebrosides, sulfatides, and sphingomyelin (Winterbourn et al., 1971), and reduced activity of CNPase, a marker for myelin and oligodendrocytes (Noguchi et al., 1983).

Myosin Va could function as a molecular motor that transports material essential for cell growth and myelin formation. Dimerized myosin Va is able to "walk" along actin cables and carry cargoes bound to myosin Va tail to the cell periphery. One 
known cargo, vesicle-associated membrane protein 2 (VAMP2), is associated with synaptic vesicles as well as oligodendrocytes but has unknown function in this cell type (Madison et al., 1999). Another associated protein, brain-expressed RING finger protein (BERP), binds $\alpha$-actinin- 4 and may anchor myosin to subcellular domains, such as endosomes (El-Husseini and Vincent, 1999).

Here, we describe the effect of myosin Va deficiency in myelin formation and oligodendrocyte cell growth. We found myelination is severely impaired in the brains and spinal cords of myosin Va-null (dilute-lethal) mice. Myosin Va was found in wild-type oligodendrocytes at all stages of oligodendrocyte maturation. Using several different techniques, we found myosin Va dysfunction leads to significantly smaller lamellas, shorter processes, and decreased process branching in oligodendrocytes. Myosin Va and VAMP2, which is a known cargo that binds myosin Va and has no effect on neuronal morphology (Zhou et al., 2000; Harms and Craig, 2005; Alberts et al., 2006), partly colocalize in oligodendrocytes. When myosin Va function is inhibited, VAMP2 localization to distal oligodendrocyte processes is blocked. Disrupting VAMP2 function causes oligodendrocytes to have smaller lamellas, shorter processes, and impaired branching, similar to what is observed for myosin $\mathrm{Va}$ functional ablation. These results establish a role for myosin Va and VAMP2 in oligodendrocyte morphogenesis and CNS myelination.

\section{Materials and Methods}

Animals and reagents. Dilute-lethal mice and Swiss Webster mice were purchased from The Jackson Laboratory (Bar Harbor, ME) and Taconic (Germantown, NY), respectively. Antibodies (Abs) for A2B5, O4, and O1 were obtained from the American Type Culture Collection (Manassas, VA); nonimmune and tagged-secondary Abs were from Jackson ImmunoResearch Laboratories (West Grove, PA); rabbit myosin Vb Abs were from BD Biosciences (San Jose, CA) and Dr. Alaa El-Husseini (University of British Columbia, Vancouver, British Columbia, Canada); mouse anti-VAMP2 and chicken anti-VAMP2 Abs were from Synaptic Systems (Goettingen, Germany) and Abcam (Cambridge, MA), respectively; mouse anti-tubulin Abs were from Upstate (Charlottesville, VA); mouse anti-VAMP2 monoclonal Abs were from Synaptic Systems. Rhodamine-phalloidin was from Invitrogen (Carlsbad, CA). Abs for myosin Va and poly-L-ornithine were from Sigma (St. Louis, MO); DMEM, trypsin, and N-2 supplement were from Invitrogen. PDGF and FGF were from PeproTech (Rocky Hill, NJ). Vector containing green fluorescent protein (GFP)-tagged myosin Va tail and anti-rabbit polyclonal myosin Va antibodies were generously provided by Dr. Paul Bridgman (Washington University, St. Louis, MO).

Primary cell culture. Primary cultures of oligodendrocytes were prepared from cerebral hemispheres of 2-d-old Sprague Dawley rats as described previously (Vartanian et al., 1997; Lehnardt et al., 2002). Purified oligodendrocytes were plated on poly-L-ornithine-coated dishes and incubated in the presence of $10 \mathrm{ng} / \mathrm{ml}$ PDGF and basic FGF for $2-3 \mathrm{~d}$. To produce differentiated oligodendrocytes, cells were incubated in serumfree media with $\mathrm{N} 2$ supplement for another $3 \mathrm{~d}$. Cells were dissociated with trypsin for $3 \mathrm{~min}$ at $37^{\circ} \mathrm{C}$, followed by trituration by pipette.

Cell treatments. After purification, 2- to 3-d-old oligodendrocytes were used for experimental conditions and treatments. Oligodendrocytes were transfected with myosin Va tail containing plasmids via Nucleofection methodology (Amaxa, Gaithersburg, MD). Forty-eight hours after transfection, cells were fixed and stained for actin. We also used a novel method whereby blocking antibodies can be transfected into cells using Chariot carrier (Activ Motif, Carlsbad CA). After trypsinization, cells were allowed to adhere to substrate for $1 \mathrm{~h}$ before transfecting with antibodies. By immunostaining for transfected antibodies, we consistently found a transfection rate of $\sim 80 \%$.

We also treated cells with 2,3-butanedione monoxime (BDM; Sigma) or tetanus neurotoxin (TENT; Calbiochem, La Jolla, CA). After trypsinization, cells were allowed to adhere for $1 \mathrm{~h}$ before exposure to $\mathrm{BDM}$ or TENT.
Cell staining and measurements. Cell death was quantified by live/dead staining techniques (Invitrogen). Process length $(n=100 \pm 50)$, process number $(n=35 \pm 15)$, branch point numbers $(n=35 \pm 15)$, and lamellar area $(n=100 \pm 50)$ were calculated using IPLab software after cells were stained with actin/tubulin. Experiments were performed independently two to three times. For actin staining, we selected only lamellas at the tips of processes and excluded other actin + areas from our measurements. Intensity measurements were performed at each $10 \%$ mark along the length of each oligodendrocyte process $(n=20-50$ approximately). Oligodendrocyte maturation was assessed by calculating the percentage of O1/olig2 cells. For all measurements, brightness and contrast were unmodified for each picture so that all cells were assessed using identical criteria.

Western analysis. Tissue was isolated from adult Swiss Webster mice and homogenized in extraction buffer (20 mM Tris- $\mathrm{HCl}, \mathrm{pH} 7.5,150 \mathrm{~mm}$ $\mathrm{NaCl}, 1$ mm EDTA, 1 mм EGTA, 1\% Triton X-100, and protease inhibitor mixture). The homogenates were electrophoresed by SDS-PAGE. Blots were blocked with 5\% milk in TBST for $1 \mathrm{~h}$ at room temperature followed by primary antibody hybridization at $4^{\circ} \mathrm{C}$ overnight. HRPconjugated secondary antibodies were used $(1: 10,000)$ for the detection, followed by enhanced chemiluminescence development (Amersham Biosciences, Piscataway, NJ).

Electron microscopy. Postnatal day 15 (P15) mice were perfused with double aldehyde fixative transcardially. Small blocks were taken from brain, optic nerve, spinal cord, and sciatic nerve, and postfixed with $1 \%$ osmium oxide, dehydrated in alcohol series and propylene oxide before embedding in Epon. One-micrometer-thick sections were cut and stained with toluidine blue. Thin sections were contrasted with uranyl acetate and lead citrate and imaged with JEOL (Peabody, MA) 1200EX electron microscope.

\section{Results \\ Analysis of myosin Va expression}

We initially confirmed by Western blot that myosin Va protein expression occurs in the CNS (Fig. $1 E$ ). We found that a $\sim 200$ $\mathrm{kDa}$ band corresponding to myosin Va decreases slightly with age in brain, whereas increases in MBP are clearly seen at P14, the initial developmental stage of brain myelination. We then determined that myosin $\mathrm{Va}$ is expressed by cortical neurons, astrocytes, microglia, and oligodendrocytes in culture (Fig. 1) (data not shown), consistent with the known localization patterns of myosin Va in brain and CNS cell types (Espreafico et al., 1992; Bridgman, 1999; Stachelek et al., 2000; Rodriguez and Cheney, 2002; Tilelli et al., 2003).

To determine subcellular localization of myosin Va and expression during oligodendrocyte maturation, we conducted immunocytochemistry experiments using cultured purified oligodendrocytes. We found that both myosin $\mathrm{Va}$ and myosin $\mathrm{Vb}$ are expressed by $\mathrm{A} 2 \mathrm{~B} 5+, \mathrm{O} 4+$, and $\mathrm{O} 1+$ oligodendrocytes. At all stages of maturation, myosin Va localized chiefly to microtubules and less to actin-rich regions, suggesting that the majority of myosin Va may not be actively interacting with F-actin. Interestingly, a portion of myosin $\mathrm{Va}$ also strongly localized to lamellas in A2B5+ oligodendrocytes (Fig. 1 A, C), suggesting that myosin Va may have more actin ATPase activity in lamellas of oligodendrocytes at this maturation stage. We also conducted myosin $\mathrm{Vb}$ immunostaining, finding that myosin $\mathrm{Vb}$ is also expressed at all stages of oligodendrocyte maturation (Fig. $1 B$ ). Both myosin Va and myosin $\mathrm{Vb}$ immunostaining were vesicular in appearance, suggesting a role in vesicular transport (Fig. 1D).

\section{Functional significance of myosin $\mathrm{Va}$ in oligodendrocyte morphogenesis}

We investigated the morphogenic role of myosin $\mathrm{Va}$ in oligodendrocytes by interfering with myosin $\mathrm{Va}$ function in these cells. After transfecting myosin $\mathrm{Va}$ tail [dominant-negative (DN)- 
myosin $\mathrm{Va}$ ], known to act as a dominant negative (Bridgman, 1999), into oligodendrocytes by nucleofection, we cultured the cells for an additional $48 \mathrm{~h}$ before fixation and staining with rhodamine-phalloidin. Because several groups suggest lamella formation may serve as a good model for myelin sheath formation because the lamellum resembles an "unfurled" myelin sheath (Kachar et al., 1986; Fox et al., 2006; Kim et al., 2006), we examined lamella surface area as well as primary process length, process branching, and primary process number. We found that DN-myosin $\mathrm{Va}$ transfection decreased lamella surface area (Fig. 2D) when compared with transfections of GFP alone (Fig. $2 A, B$ ). In contrast, DN-myosin Va did not appear to restrict length of filopodia, which are small diameter $(\sim 100-200 \mathrm{~nm})$ outgrowths from larger morphologic features like lamella processes or cell bodies. We also found that DN-myosin Va transfection significantly reduced oligodendrocyte process length, number, and branching (Fig. 2C,E,F).

To confirm these findings, we transfected myosin Va blocking antibodies into oligodendrocytes and compared morphologic changes to transfections using equivalent amounts of isotype-matched nonimmune antibodies. Transfections of myosin Va blocking antibodies caused significant reductions in both process length and lamella size in a time-dependent manner (Fig. $2 I$, J, respectively). In addition, process branching was also significantly reduced at $18 \mathrm{~h}$ (Fig. $2 \mathrm{~L}$ ). Process number was not affected by myosin Va blocking antibodies, most likely because antibodies were introduced to oligodendrocytes later in morphogenesis and for shorter time intervals, compared with transfections. To determine whether oligodendrocyte maturation is blocked in parallel with morphogenesis, we stained cells with olig2, expressed at all stages of maturation, and O1, expressed only by mature oligodendrocytes, after cells were treated with myosin Va blocking antibodies and cultured for $48 \mathrm{~h}$. We found no effect of myosin $\mathrm{Va}$ ablation on oligodendrocyte maturation (data not shown), indicating that myosin Va appears to specifically affect oligodendrocyte morphogenesis.

As another control, we transfected myosin $\mathrm{Vb}$ antibodies into oligodendrocytes to determine whether myosin $\mathrm{Vb}$ also had similar effects on oligodendrocyte growth patterns. Transfections using myosin $\mathrm{Vb}$ antibodies did not affect any measured parameter of oligodendocyte morphology (Fig. 3), suggesting myosin $\mathrm{Va}$, but not myosin $\mathrm{Vb}$, controls many aspects of oligodendrocyte morphogenesis.

In addition, to further confirm the importance of myosin Va in oligodendrocyte morphogenesis, we treated oligodendrocytes with BDM, a relatively specific inhibitor of myosin Va (Cramer and Mitchison, 1995; Uemura et al., 2004). We found that BDM significantly blocked process elongation and lamella formation in
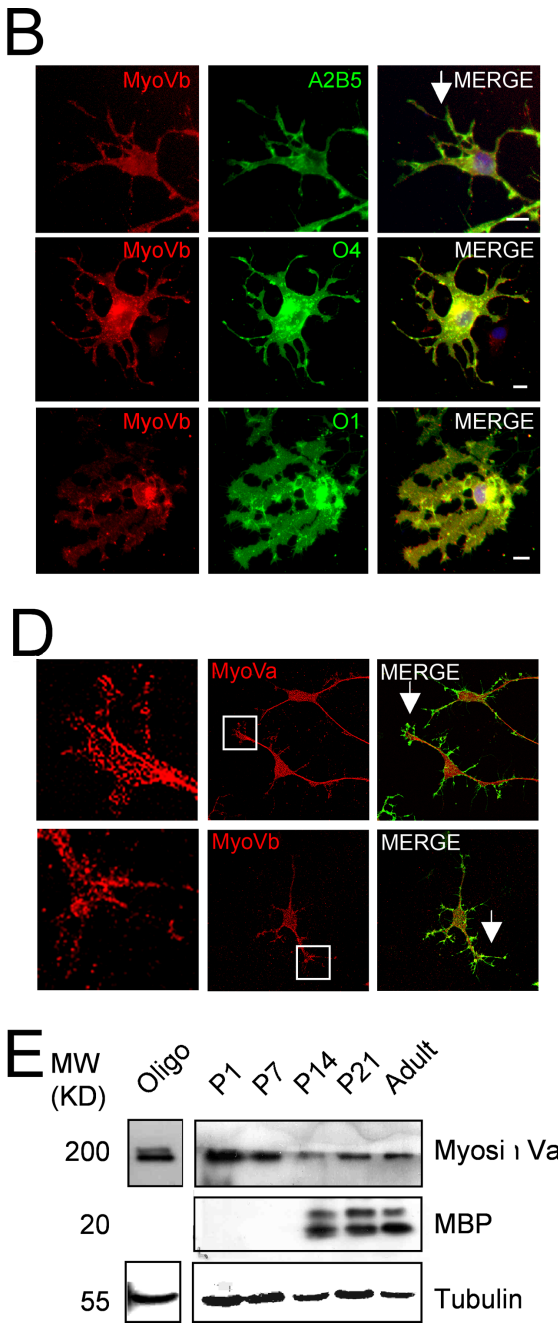

Figure 1. Expression of myosin Va in brain and oligodendrocytes. $\boldsymbol{A}, \boldsymbol{B}$, Purified oligodendrocytes were stained for myosin Va fores) or myosin $\mathrm{Vb}$ (bottom figures). The inset figures of both are to the left. The arrows indicate examples of lamellas

a dose-dependent manner (Fig. $4 D, E$ ). In addition, BDM significantly inhibited process formation and branching (Fig. $4 F, G$ ). When BDM was washed out of the culture media, oligodendrocytes returned to a state of rapid process growth and lamella formation (Fig. 4C), indicating that the effects of BDM are reversible and nontoxic. In addition, we found no significant differences in cell death when cells were treated with myosin Va blocking antibodies or by BDM (data not shown). Therefore, using three independent methods, we found that myosin Va function is critically important to oligodendrocyte morphogenesis but not cell death or maturation.

\section{Association between VAMP2 and myosin Va}

Synaptobrevins (Coco et al., 1999; Kimura et al., 2003; Singh et al., 2004; Ewart et al., 2005) and soluble $N$-ethylmaleimidesensitive factor attachment protein receptor (SNARE) proteins in general (Zhou et al., 2000; Kimura et al., 2003; Sakisaka et al., 2004; Darios and Davletov, 2006) are essential to cell growth by providing new plasma membrane to sites of growth. A v-SNARE, VAMP2 is known to complex with myosin V in brain extracts (Prekeris and Terrian, 1997; Ohyama et al., 2001) and both VAMP2 and myosin V associate with synaptic vesicles in neurons 

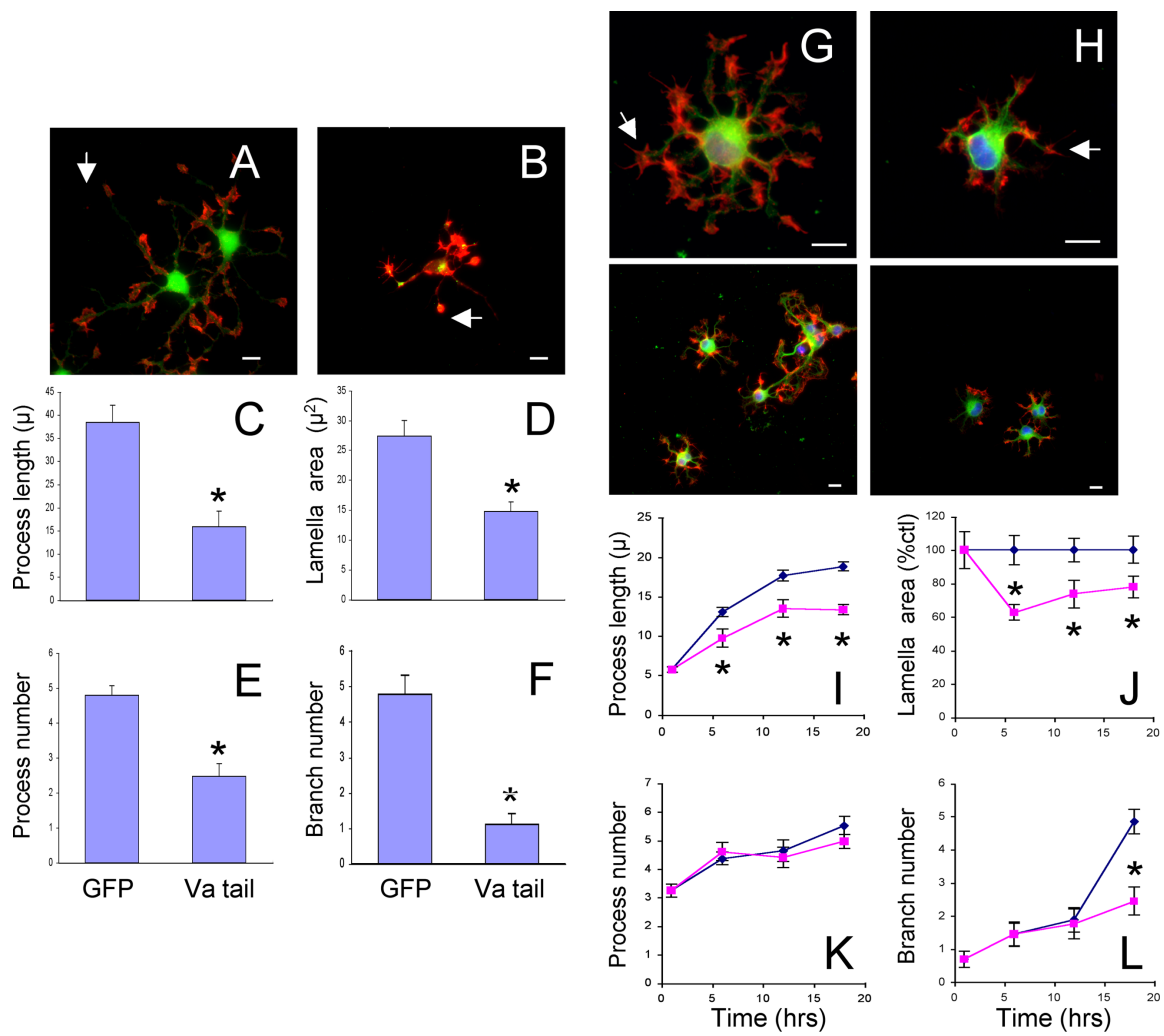

Figure 2. Myosin Va promotes lamella growth, process extension, and process branching. $\boldsymbol{A}-\boldsymbol{F}$, Purified oligodendrocytes were transfected with GFP alone (A) or GFP-myosin Va tail (B). Cells shown exhibit GFP fluorescence (green) and are stained with rhodamine-phalloidin (red). Primary process length (in micrometers) $(\boldsymbol{C}$ ), lamella surface area (in square micrometers) $(\boldsymbol{D})$ primary process number $(\boldsymbol{E})$, and branch number $(\boldsymbol{F})$ were measured for both GFP and GFP-myosin Va tail transfected cells. $\mathbf{G}-\boldsymbol{L}$, Purified oligodendrocytes were transfected with nonimmune rabbit antibody $(\boldsymbol{G})$ or blocking myosin Va antibodies $(\boldsymbol{H})$ and subsequently stained for actin (red), tubulin (green), and 4',6' -diamidino-2-phenylindole (DAPI) (blue). The images show high (top) and low (bottom) magnification fields. Cells were fixed at 1,6, 12, and $18 \mathrm{~h}$ after replating and transfection. Primary process length (in micrometers) $(\boldsymbol{I})$, lamella surface area $(\boldsymbol{J})$, primary process number $(\boldsymbol{K})$, and branch number $(\boldsymbol{L})$ were measured for both control antibody and myosin Va-transfected cells. The pink squares represent measurements of myosin Va antibody transfected oligodendrocytes and the blue circles represent measurements of control transfected oligodendrocytes. Morphologic traits of $\mathbf{1 8}-\mathbf{2 1}$ cells were measured for experiments in $\boldsymbol{A}-\boldsymbol{F}$ and $35-37$ cells in $\mathbf{G} \mathbf{L}$. Error bars represent SEM. The asterisk indicates $p<$ 0.05 by $t$ test. The arrows indicate examples of lamellas. Scale bars, $10 \mu \mathrm{m}$.
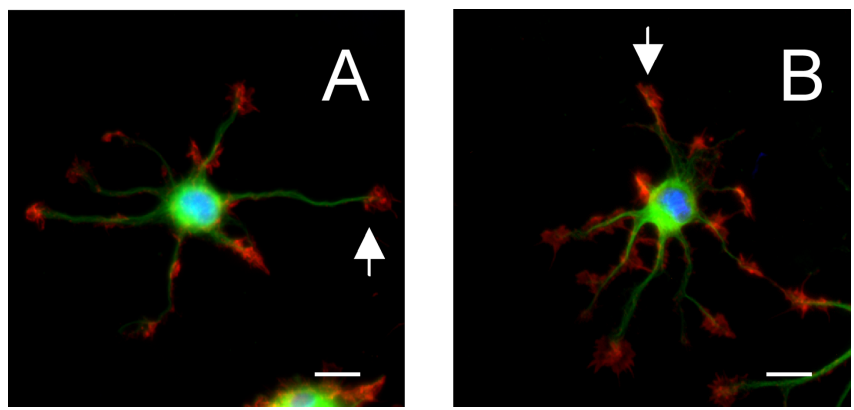

Figure 3. Myosin Vb antibodies do not affect oligodendrocyte morphogenesis. $\boldsymbol{A}, \boldsymbol{B}$, Purified oligodendrocytes were transfected with nonimmune rabbit antibody $(\boldsymbol{A})$ or myosin Vb antibodies (B) and subsequently stained for actin (red), tubulin (green), and DAPI (blue). Cells were fixed at $18 \mathrm{~h}$ after replating and transfection. The arrows indicate examples of lamellas. Scale bars, $10 \mu \mathrm{m}$.

(Prekeris and Terrian, 1997; Bridgman, 1999). In oligodendrocytes, VAMP2 is upregulated with oligodendrocyte maturation, localized to oligodendrocyte process branch points and distal processes, and found in myelinating oligodendrocytes in vivo (Madison et al., 1999). Other proteins, including BERP, complex with myosin $\mathrm{Va}$, but their importance to cell function is relatively unexplored (ElHusseini and Vincent, 1999).

We tested whether VAMP2 and BERP proteins are expressed in oligodendrocytes and associate with myosin $\mathrm{Va}$ within this cell type. We confirmed that VAMP2 localizes to oligodendrocyte processes at all stages of maturation and that BERP is also expressed by oligodendrocytes (Fig. 5). Although BERP localization is not appreciably altered during oligodendrocyte maturation, VAMP2 localizes to filopodia and lamellipodia of A2B5+ oligodendrocytes, suggesting a role for VAMP2 at this stage of maturation. We also show that VAMP2 is expressed during development while myelin is forming in brain (Fig. 5C).

In A2B5+ oligodendrocytes, VAMP2 localization changes from primarily cytosolic to localizing in lamellas and filopodia. This change in subcellular localization correlates with A2B5+ oligodendrocyte process elongation (Fig. $5 A$ ). As a transport protein, myosin Va may be associated with VAMP2, whereas VAMP2 is mostly cytosolic and vesicular but not when VAMP2 is localized to filopodia and presumably associated with the plasma membrane. We therefore assessed whether myosin Va localizes with VAMP2 in both stages of A2B5+ cells. In A2B5+ cells with cytosolic localization of VAMP2, myosin Va colocalized extensively with VAMP2 (Fig. 6A). In contrast, there was less colocalization of myosin Va once VAMP2 begins to be found in lamellas and filopodia (Fig. 6A). For BERP, we found that myosin $\mathrm{Va}$ and BERP colocalized extensively independent of developmental stage (Fig. 6A). Therefore, myosin Va appears to associate with both BERP and cytosolic VAMP2 in oligodendrocytes.

\section{Myosin Va functions in VAMP2 localization}

To test whether myosin Va controls VAMP2 localization to the distal process of the oligodendrocyte (i.e., lamellas and filopodia), we transfected myosin Va blocking antibodies into oligodendrocytes and immunostained for VAMP2 (Fig. 6C). By measuring the intensity of VAMP2 staining along the length of the oligodendrocyte process, we found that VAMP2 staining intensity was significantly reduced in distal filopodia and the distal process (the distal one-tenth of the process). In contrast, the staining intensity of BERP was not significantly altered in the distal oligodendrocyte process. Both VAMP2 and BERP staining intensities were increased in proximal processes, suggesting that myosin Va controls the localization of both proteins proximally but only VAMP2 in distal processes. This may be a product of different functions of BERP and VAMP2 or binding dynamics with myosin Va.

As another approach, we nucleofected oligodendrocytes with GFP-tagged DN-myosin Va and stained for VAMP2 (Fig. 6B). VAMP2 was not found in filopodia or lamellas of oligodendrocytes and was instead localized to regions just proximal to lamel- 

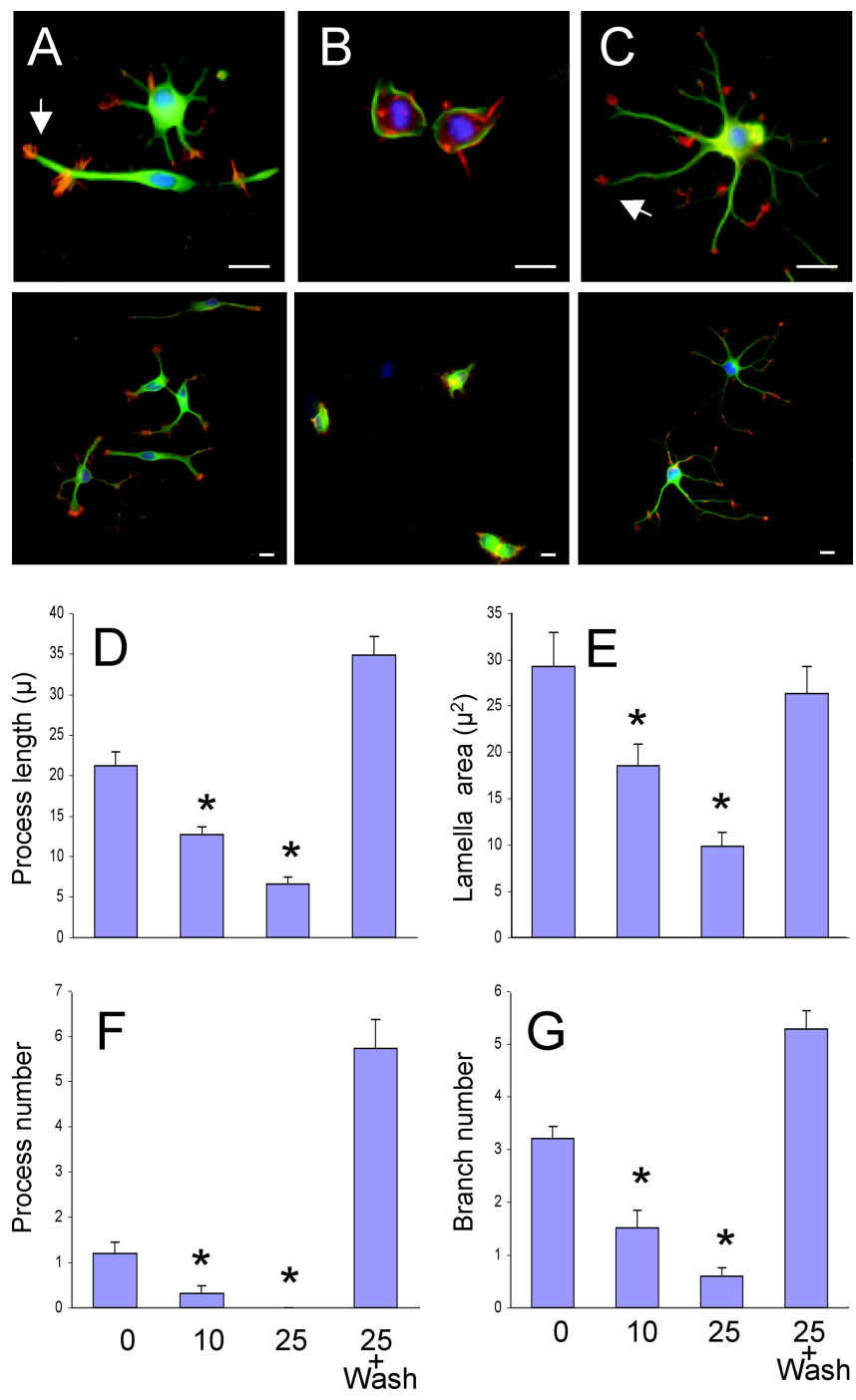

Figure 4. Alterations to oligodendrocyte morphogenesis by BDM treatment. Purified oligodendrocytes were replated and cultured with 0,10 , or $25 \mu \mathrm{m}$ BDM for $6 \mathrm{~h}$, fixed, and stained for actin (red), tubulin (green), and DAPI (blue). $\boldsymbol{A}$ shows control oligodendrocyte, and $\boldsymbol{B}$ shows 25 $\mu \mathrm{M}$ BDM-treated oligodendrocyte after $6 \mathrm{~h}$ culture. A subset of cells was treated with $25 \mu \mathrm{m}$ BDM for $6 \mathrm{~h}$, washed, and cultured for an additional $24 \mathrm{~h}$ before fixation (C). Images show high (top) and low (bottom) magnification fields ( $\boldsymbol{A}-\boldsymbol{C}$. Primary process length (in micrometers) $(\boldsymbol{D})$, lamella surface area $(\boldsymbol{E})$, primary process number $(\boldsymbol{F})$, and branch number $(\boldsymbol{G})$ were measured for control and BDM-treated cells. Error bars represent SEM. The asterisk indicates $p<$ 0.05 by $t$ test. The arrows indicate examples of lamellas. Scale bars, $10 \mu \mathrm{m}$.

las. In addition, a significant amount of VAMP2 was retained in cell bodies. Consistent with colocalization and physical association of myosin Va and VAMP2, most VAMP2 staining colocalized with GFP-tagged DN-myosin Va. Thus, myosin Va appears to control VAMP2 localization at the distal regions of the oligodendrocyte process.

\section{VAMP2 function in oligodendrocyte morphogenesis}

Similar to myosin Va, VAMP2 does not appear to interfere significantly with neuronal growth cone formation and neurite growth patterns (Zhou et al., 2000; Harms and Craig, 2005; Alberts et al., 2006). Because we found that functional ablation of myosin Va promoted defects in oligodendrocyte morphogenesis and altered VAMP2 localization, we predicted that ablation of VAMP2 function would lead to comparable deficits in oligodendrocyte growth patterns.
To test whether VAMP2 has a similar role in oligodendrocyte morphogenesis as myosin Va, we transfected oligodendrocytes with VAMP2 blocking antibodies. After $18 \mathrm{~h}$ treatment, cells exhibited significantly smaller lamella area, shorter processes, and decreased process branching (Fig. 7). Although BERP blocking antibodies also affected oligodendrocyte morphology, there was no effect on lamella surface area (Fig. $7 F$ ), indicating that BERP has a distinctly different role in morphogenesis.

To test the function of VAMP2 by an independent method, we treated cells with TENT, which is known to selectively cleave VAMP2 (Singh et al., 2004). In a dose-dependent manner, TENT significantly inhibited process elongation and lamella growth of oligodendrocytes at $6 \mathrm{~h}$ (Fig. $8 A-D$ ). Process branching was also significantly inhibited by $100 \mathrm{~mm}$ TENT for $6 \mathrm{~h}$ (Fig. $8 \mathrm{~F}$ ). Therefore, VAMP2 has a similar function to myosin Va in oligodendrocyte process elongation, lamella spreading, and process branching.

\section{Myosin Va-null mice exhibit hypomyelination}

To determine whether loss of myosin Va function promotes a defect in myelination in vivo, we examined the ultrastructural detail of the corpus callosum, optic nerve, and spinal cord of myosin Va-null (dilute-lethal) mice compared with littermate controls. Sections were prepared from P15 animals for electron microscopy. Compared with controls, toluidine blue staining showed hypomyelination in CNS structures including the cervical spinal cord, thoracic cord, lumbar cord, optic nerve, and corpus callosum, but not PNS structures including the sciatic nerves or oculomotor nerves (data not shown). Electron microscopic analysis on cervical cord, optic nerve, and corpus callosum showed a significant reduction in percent myelinated fibers as well as increase in $g$-ratio [0.6896 \pm 0.0146 (SEM) for wild type and $0.7702 \pm 0.0136$ for myosin Va-null corpus callosum; $p<$ 0.0002 by $t$ test] (Fig. $9 A-D$ ). In terms of axonal diameter and numbers, we found no difference in unmyelinated and myelinated axonal caliber and noted no difference in axonal densities. In addition, we found reduced MBP expression in myosin Va-null mouse brain compared with wild-type control (Fig. 9E). Together, these in vivo findings suggest that lack of myosin Va results in deficient myelination of the optic nerve, spinal cord, and corpus callosum.

Myelination is a complex process involving cell-cell regulation between oligodendrocyte lamellas and axons of neurons, and the dramatic cell spreading or growth of oligodendrocyte lamellas. These studies link myosin Va with the function of generating the oligodendrocyte lamellum and the myelin sheath.

\section{Discussion}

In this report, we describe the role of myosin Va in oligodendrocyte morphogenesis and myelination. Using oligodendrocytes in culture, we found that myosin Va plays an important role in determining lamella size and process number, branching, and length. In contrast, we found no effect on oligodendrocyte cell death or maturation when myosin Va function is disrupted. Because myosin $\mathrm{Va}$ appears only to affect oligodendrocyte morphology in culture, we believe that abnormal oligodendrocyte morphology is responsible for the observation of impaired myelination in brains and spinal cords of myosin Va-null (dilutelethal) mice.

The hypothesis that oligodendrocyte morphology is critical for myelination is logical especially because several sources indicate the importance of the oligodendrocyte cytoskeleton and corresponding morphology to myelination in vitro (Kachar et al., 

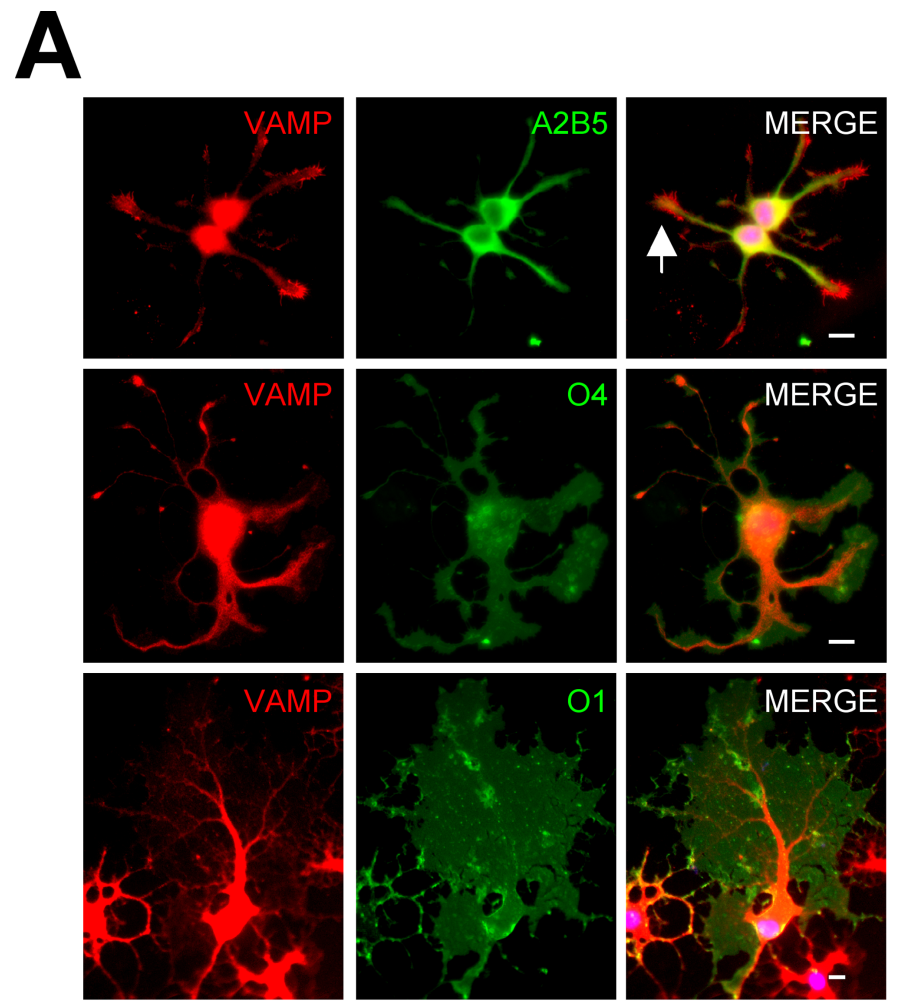
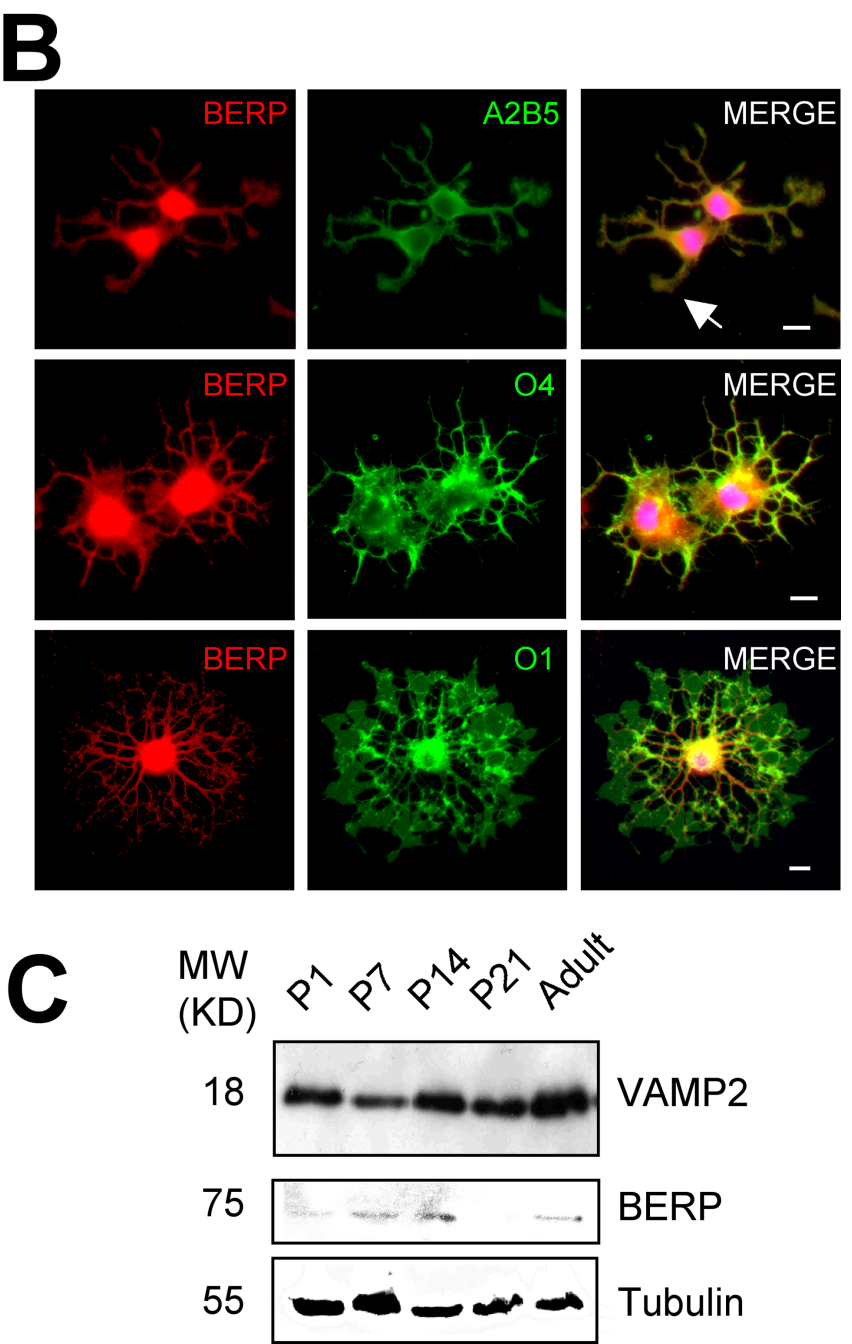

Figure 5. Expression of VAMP2 and BERP in brain and oligodendrocytes. $A$, VAMP2 is expressed in all stages of oligodendrocyte maturation. Note localization of VAMP2 to filopodia and lamellipodia only at A2B5 stage. B, BERP is expressed at all stages of oligodendrocyte maturation. There is no alteration of BERP localization at A2B5 stage. The arrows indicate examples of lamellas. Scale bars, $10 \mu \mathrm{m}$. C, Developmental profile of VAMP2 and BERP during period of myelination. Levels of VAMP2 but not BERP increase in brain during developmental period of myelination.

1986; Wilson and Brophy, 1989; Hardy and Friedrich, 1996; Buttery and ffrench-Constant, 2001; Song et al., 2001). For example, electron microscopic studies have shown that as many as 50 internodes originate from a single oligodendrocyte in vivo (Raine, 1997). Therefore, if process number or branching is reduced, one might expect a corresponding decrease in internodes.

In addition to process number and branching, other morphologic features of oligodendrocytes are likely critical to myelination, including process length and lamella formation. In vitro studies demonstrate that before myelin formation, an oligodendrocyte process extends parallel to an axon (Hardy and Friedrich, 1996). Subsequently, the oligodendrocyte process elaborates a local thickening or lamella that initiates the formation of the myelin internode. The final myelin sheath is a product of spiraling of this lamella and associated process around the axon segment to form multiple compacted wrappings that are characteristic of the sheath. The growth of lamellas appears to be tied to process outgrowth, consistent with other cell types (Fox et al., 2006). Our laboratory has also found that Wiskott-Aldrich syndrome protein-family verprolin-homologous protein 1 (WAVE1), a key regulator of actin nucleation and essential for lamellipodia formation, is also required for proper lamella formation and myelination by oligodendrocytes (Kim et al., 2006).
Therefore, both process extension and lamella formation appear to be critical phenomena to the formation of myelin.

Because myosin Va functional ablation impairs oligodendrocyte process formation, elongation, and branching as well as lamella formation, all four abnormalities are linked and may arise from one another. WAVE1, which controls lamella formation in oligodendrocytes and other cell types (Kim et al., 2006), also is critical for increasing process numbers, length, and branching (data not shown). Therefore, lamella formation may be the essential cellular phenomena regulated by myosin $\mathrm{Va}$ in addition to WAVE1. Other morphology may arise as a consequence of perturbations to lamella morphology and/or function. Surprisingly, these relationships in eukaryotic cellular morphogenesis appear to be relatively unstudied.

Interestingly, VAMP2, a protein that associates with myosin Va (Prekeris and Terrian, 1997; Ohyama et al., 2001), localizes to lamellas along with myosin $\mathrm{Va}$ and also appears to be critically important to determining lamella size and process number, branching, and length. Because localization of VAMP2 to distal processes was disrupted by inhibiting myosin Va function, we concluded that myosin $\mathrm{Va}$ functions to transport or localize VAMP2 to distal processes of oligodendrocytes. However, confirming that the two proteins interact (Prekeris and Terrian, 1997) has 

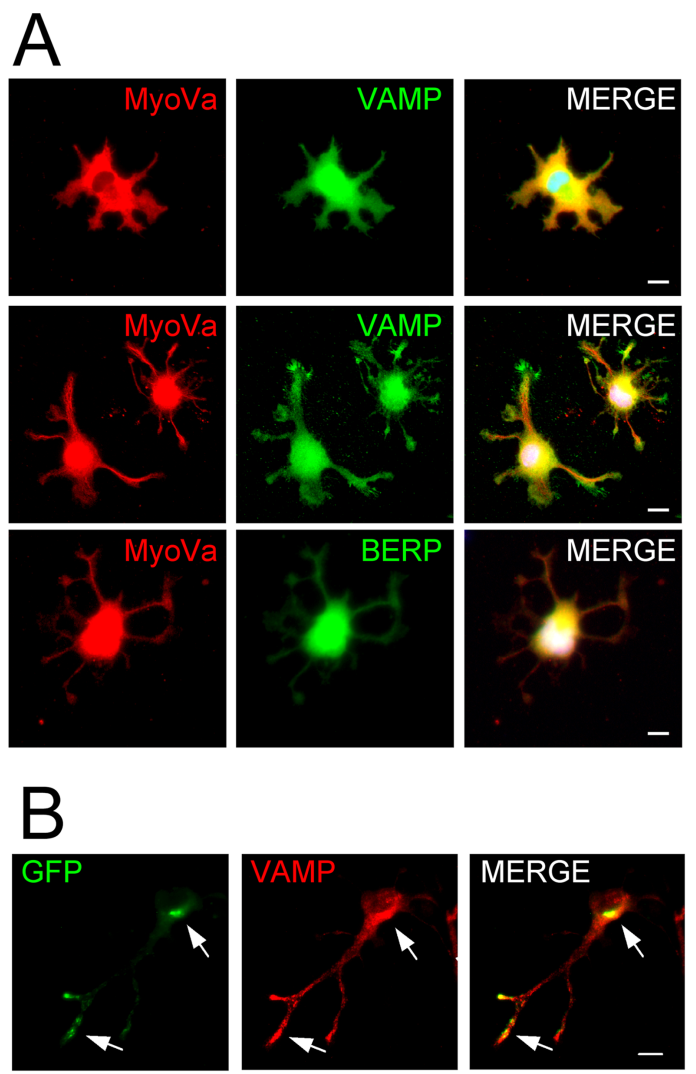

C

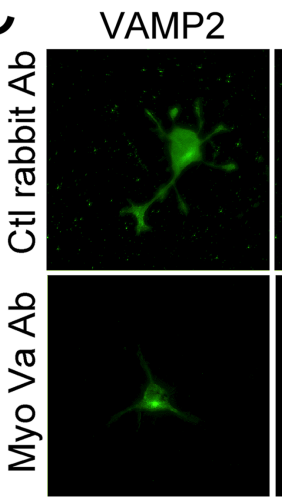

MERGE
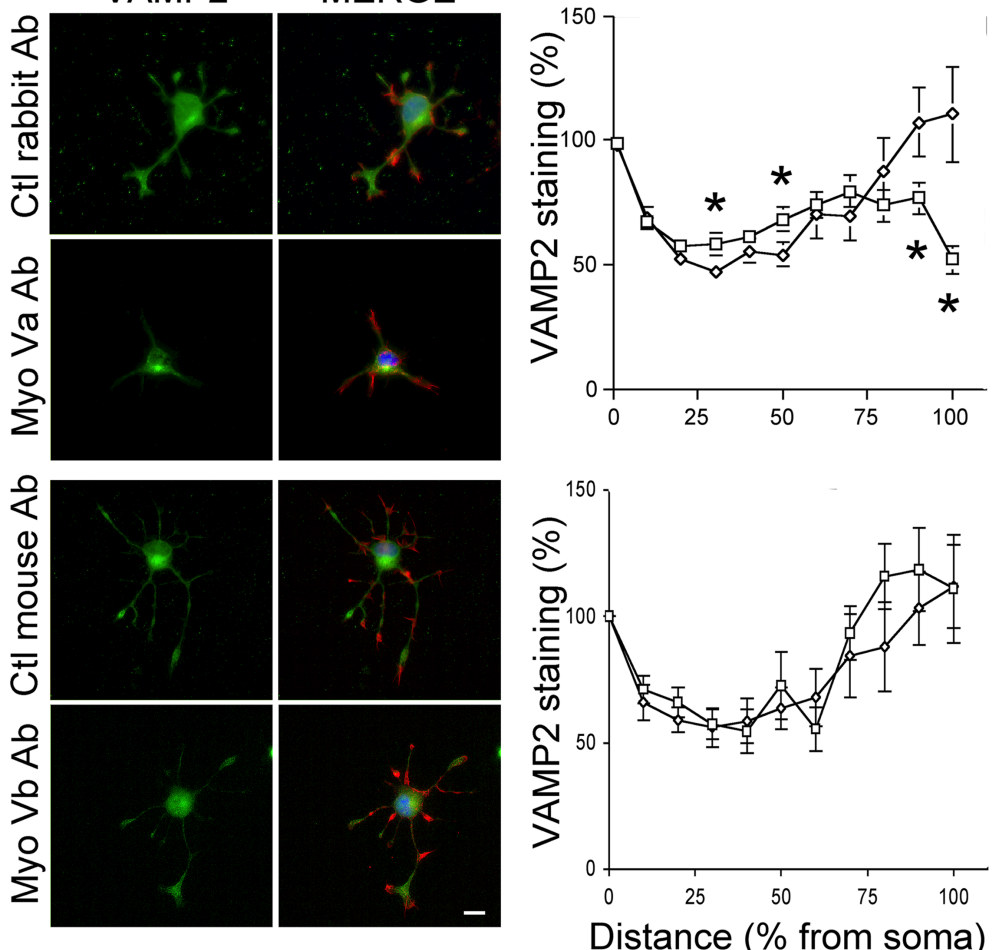

$\mathrm{D}$
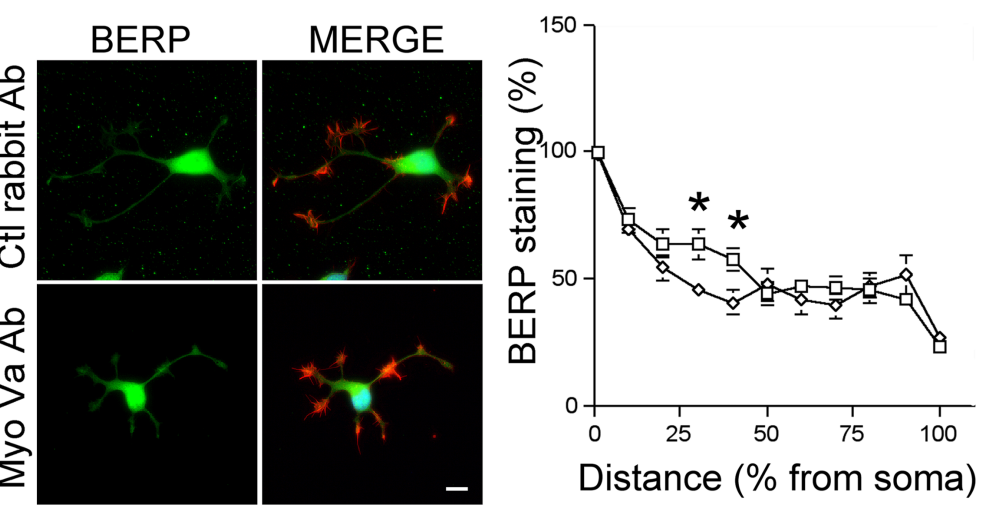

Distance (\% from soma)

Figure 6. Myosin Va controls localization of VAMP2 to distal processes of oligodendrocytes. A, Purified oligodendrocytes at the A2B5 stage of maturation were stained for myosin Va, VAMP2, or BERP. As A2B5 type oligodendrocytes elaborate processes, VAMP2 becomes more distally localized to process tips and filopodia. VAMP2 localized to lamellas and filopodia does not colocalize with myosin Va, whereas more proximal VAMP2, including in distal process, does colocalize with myosin Va. BERP and myosin Va colocalize in A2B5 type oligodendrocytes. The arrows indicate examples of lamellas. B, GFP-tagged DN-myosin Va was nucleofected into oligodendrocytes, which were stained for VAMP2. VAMP2 does not localize to filopodia of oligodendrocyte distal processes and instead forms collections in the distal processes that colocalize with GFP-myosin Va tail signal. The arrows show regions of colocalization between GFP and endogenous VAMP2. C, VAMP2 localization is disrupted by blocking antibodies to myosin Va but not myosin Vb. Purified oligodendrocytes were replated and transfected with myosin Va blocking antibodies or control rabbit antibodies (top figures) or with myosin Vb blocking antibodies or control mouse antibodies (bottom figures). Cells were cultured for $6 \mathrm{~h}$ and stained for VAMP2 (green), actin (red), and DAPI (blue). In most distal processes transfected with control or myosin Vb antibodies, VAMP2 localization to distal processes clearly occurs. Cells transfected with myosin Va blocking antibodies had significantly less VAMP2 staining. Data from myosin $\mathrm{Va}$ (squares) or control (diamonds) transfected cells is displayed in top graph. Data from myosin Vb (squares) or control (diamonds) transfected cells is displayed in the bottom graph. D, Similar to VAMP2, BERP staining intensity increased proximally after myosin Va blocking antibody transfection. However, there were no differences distally. Data from BERP (squares) or control (diamonds) transfected cells is displayed in the graph to the right. For both $\mathbf{C}$ and $\boldsymbol{D}$ graphs, staining intensity was converted to percentage intensity found at the proximal root of each process. Intensities were plotted per decile of process length to allow comparison of processes of differing length. Error bars represent SEM. The asterisk indicates $p<0.05$ by $t$ test. Scale bars, $10 \mu \mathrm{m}$.

been particularly vexing to us, because we have not been able to immunoprecipitate complexes of VAMP2 and myosin Va, although several attempts with different conditions have been tried. At present, we are uncertain why complexes have not immunoprecipitated, but it remains a possibility that the association between VAMP2 and myosin Va is weak, unstable, or transient in nature. In general, associations between brain myosin $\mathrm{Va}$ and other proteins, including VAMP2, TLS, and Nd1-L, have already been found to be highly regulated by the presence of calcium (Prekeris and Terrian,
1997; Yoshimura et al., 2006). In addition, VAMP2 localization and function is heavily regulated by other SNARE machinery and signaling, including PKA (protein kinase A), PKC (protein kinase C), PI3K (phosphoinositide-3 kinase), and PKD (protein kinase D) (Torok et al., 2004; Yoshida and Mishina, 2005; Oh and Thurmond, 2006). Phosphorylation of VAMP2 may also play a role in its binding properties (Braiman et al., 2001; Fritzius et al., 2007).

Despite our observation that myosin Va appears to control VAMP2 localization, it is possible that myosin Va could regulate 

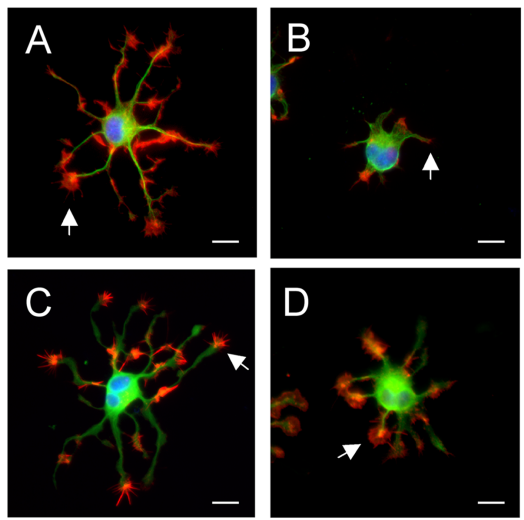
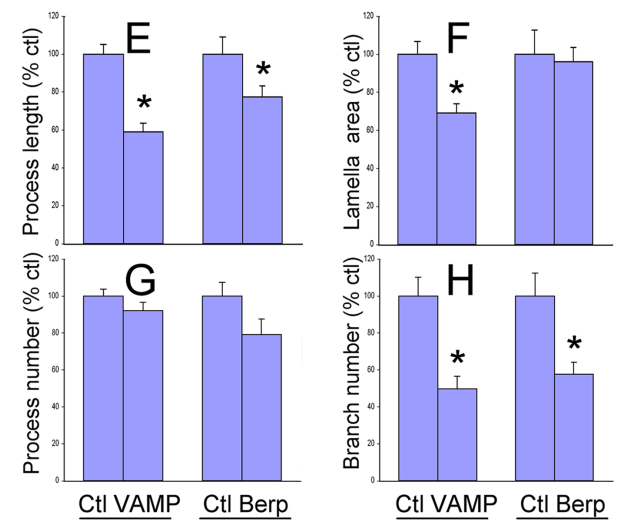

Figure 7. Functional ablation of VAMP2 but not BERP inhibits oligodendrocyte morphogenesis. $\boldsymbol{A}-\boldsymbol{D}$, Cells were transfected with nonimmune chicken antibody $(\boldsymbol{A})$, blocking VAMP2 antibodies $(\boldsymbol{B})$, nonimmune mouse antibody $(\boldsymbol{C})$, or blocking BERP antibodies (D) and subsequently stained for actin (red), tubulin (green), and DAPI (blue). Cells were fixed at $18 \mathrm{~h}$ after replating and transfection. Primary process length (in micrometers) $(\boldsymbol{E})$, lamella surface area $(\boldsymbol{F})$, primary process number $(\boldsymbol{G})$, and branch number $(\boldsymbol{H})$ were measured for both control antibody and VAMP2/BERP antibody transfected cells. Error bars represent SEM. The asterisk indicates $p<0.05$ by $t$ test. The arrows indicate examples of lamellas. Scale bars, $10 \mu \mathrm{m}$.
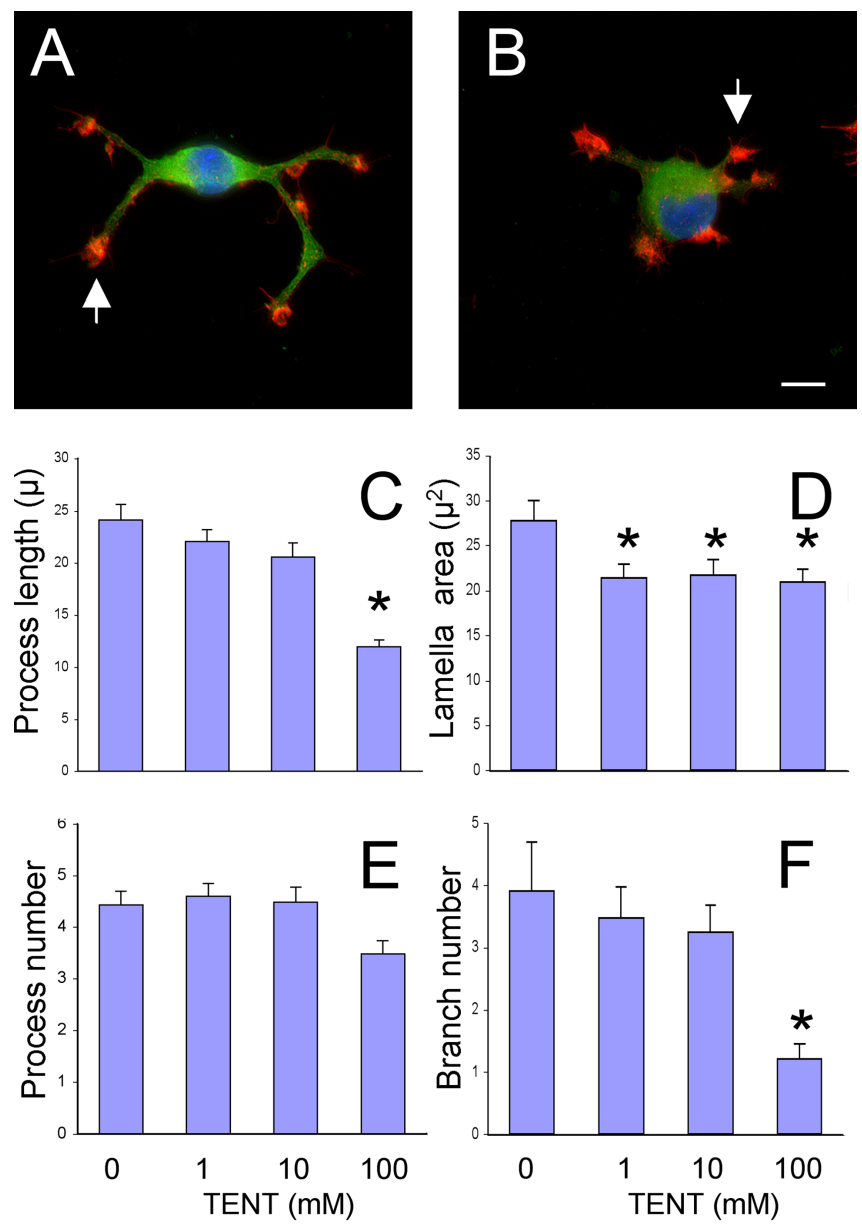

Figure 8. Alterations to oligodendrocyte morphogenesis by TENT treatment. $\boldsymbol{A}, \boldsymbol{B}$, Purified oligodendrocytes were plated and treated with $0,1,10$, or $100 \mu \mathrm{m}$ TENT for $18 \mathrm{~h}$. Cells were fixed and stained for actin (red) and by DAPI (blue). $\boldsymbol{A}$ shows control oligodendrocyte, and $\boldsymbol{B}$ shows $100 \mu \mathrm{m}$ TENT-treated oligodendrocyte after $18 \mathrm{~h}$ culture. Primary process length (in micrometers) $(\boldsymbol{C}$ ), lamella surface area $(\boldsymbol{D})$, primary process number $(\boldsymbol{E})$, and branch number $(\boldsymbol{F})$ were measured for control and BDM-treated cells. Error bars represent SEM. The asterisk indicates $p<0.05$ by $t$ test. The arrows indicate examples of lamellas. Scale bars, $10 \mu \mathrm{m}$. oligodendrocyte morphology and myelination via other mechanisms. For example, myosin Va is known to bind and transport mRNA (Yoshimura et al., 2006). Oligodendrocytes require mRNA transport over long distances to enable myelination and potentially also other morphological changes. However, we did not see substantial changes in lamella morphology after cycloheximide treatment (data not shown), suggesting that at least in vitro findings of this report are unlikely to be a product of mRNA transport alterations. In addition, myosin $\mathrm{Va}$ is important for smooth endoplasmic reticulum (SER) localization in dendrites of cerebellar Purkinje neurons (Miyata et al., 2000) and may be important for SER localization in oligodendrocytes. In Purkinje neurons but not hippocampal neurons, inappropriate subcellular SER localization leads to impaired $\mathrm{IP}_{3}$-induced calcium release in dendritic spines and deficient long-term synaptic depression (Miyata et al., 2000; Schnell and Nicoll, 2001). There is also extensive literature on the binding of myosin Va to melanophin/RAB27A complexes, but brain myosin $\mathrm{Va}$ does not contain exon $\mathrm{F}$ that is required for melanophin binding (Wu et al., 2002). Overall, additional proteins or organelles may bind to myosin Va and play an important role in oligodendrocyte morphogenesis and myelination, but this remains incompletely explored.

It is puzzling that functional ablation of myosin $\mathrm{Va}$ affects oligodendrocyte morphology and myelination, whereas no consistent effect has been observed with neurons. In addition, because VAMP2 is also expressed by neurons, the simple presence of VAMP2 cannot account for the presence or absence of morphologic changes in different cell types (Zhou et al., 2000; Harms and Craig, 2005; Alberts et al., 2006). As discussed above, the regulation of and interactions with binding partners of myosin Va and VAMP2 may be highly important to the function of each protein. Therefore, signaling present in oligodendrocytes and not in neurons or vice versa may account for the cell type-specific alterations in function and morphology. Alternatively, proteins, mRNAs, or organelles that bind myosin Va and/or VAMP2 may be present or functionally different in one cell type versus another, and could account for functional and morphological differences between cell types. Because we are just beginning to understand myosin Va regulation and functional binding domains, more remains to be done before we can determine cell type-specific differences in protein function.

What is clear from our work, however, is that both myosin Va and VAMP2 contribute to oligodendrocyte morphology in a similar manner, that myosin Va regulates VAMP2 localization to the distal oligodendrocyte process, and that myosin $\mathrm{Va}$ is critically important for proper myelination in the brain and spinal cord. Such alterations in myelination appear to account for neurologic symptoms in myosin Va-null (dilute-lethal) mice. Dilute-lethal mice possess a mild high-frequency tremor and moderate locomotor deficits (Mercer et al., 1991; Wilson et al., 2000; Matesic et al., 2001). These mice begin to have sporadic and infrequent opisthotonic seizures at $\sim 12 \mathrm{~d}$ of age, and die at $\sim 21 \mathrm{~d}$ of age (Noguchi et al., 1983). Myosin Va-null mice exhibit a similar phenotype to animals with known myelin defects, including the shiverer (MBP-null) mouse and myelin-deficient rat, both of 
which display tremors, locomotor impairments, seizures, and premature death (Roach et al., 1983; Rosenbluth et al., 1994).

Interestingly, several GS1 patients and dilute mutant strains of mice have been known to "grow out" of their neurologic deficits. For example, certain myosin $\mathrm{Va}$ mutations in mice, including Myo5a ${ }^{\mathrm{d}-\mathrm{n}}$ and Myo5a ${ }^{\mathrm{d}-\mathrm{n} 2 J}$, exhibit neurologic impairments similar to dilute-lethal mice at $\sim 1-3$ weeks of age, but both strains show partial or complete phenotypic improvement as they age (Huang et al., 1998). Because most CNS myelination occurs over the first 3-4 weeks of life in the mouse, the same period when mice with Myo5a ${ }^{\text {d-n }}$ and Myo5a ${ }^{\mathrm{d}-\mathrm{n} 2 \mathrm{~J}}$ have maximal neurologic symptoms, it is possible that a delay in myelination is responsible for phenotypes of Myo5a ${ }^{\text {d-n }}$ and Myo5a ${ }^{\text {d-n2J }}$ mice, whereas the myosin $\mathrm{Va}$ mutation in dilute-lethal mice causes more severe defects in myelination, leading to death. The transient neurologic symptoms seen in development with milder myosin Va mutations is more compatible with delayed myelination rather than with abnormal neuronal function and should be further investigated.

\section{References}

Alberts P, Rudge R, Irinopoulou T, Danglot L, Gauthier-Rouviere C, Galli T (2006) Cdc42 and actin control polarized expression of TI-VAMP vesicles to neuronal growth cones and their fusion with the plasma membrane. Mol Biol Cell 17:1194-1203.

Anikster Y, Huizing M, Anderson P, Fitzpatrick D, Klar A, Gross-Kieselstein E, Berkun Y, Shazberg G, Gahl W, Hurvitz H (2002) Evidence that Griscelli syndrome with neurological involvement is caused by mutations in RAB27A, not MYO5A. Am J Hum Genet 71:407-414.

Bahadoran P, Ortonne J, Ballotti R, de Saint-Basile G (2003) Comment on Elejalde syndrome and relationship with Griscelli syndrome. Am J Med Genet A 116:408-409.

Braiman L, Alt A, Kuroki T, Ohba M, Bak A, Tennenbaum T, Sampson S (2001) Activation of protein kinase $\mathrm{C}$ zeta induces serine phosphorylation of VAMP2 in the GLUT4 compartment and increases glucose transport in skeletal muscle. Mol Cell Biol 21:7852-7861.

Bridgman PC (1999) Myosin Va movements in normal and dilute-lethal axons provide support for a dual filament motor complex. J Cell Biol 146:1045-1060.

Buttery P, ffrench-Constant C (2001) Process extension and myelin sheet formation in maturing oligodendrocytes. Prog Brain Res 132:115-130.

Coco S, Raposo G, Martinez S, Fontaine J, Takamori S, Zahraoui A, Jahn R, Matteoli M, Louvard D, Galli T (1999) Subcellular localization of tetanus neurotoxin-insensitive vesicle-associated membrane protein (VAMP)/VAMP7 in neuronal cells: evidence for a novel membrane compartment. J Neurosci 19:9803-9812.

Cramer L, Mitchison T (1995) Myosin is involved in postmitotic cell spreading. J Cell Biol 131:179-189.

Darios F, Davletov B (2006) Omega-3 and omega-6 fatty acids stimulate cell membrane expansion by acting on syntaxin 3. Nature 440:813-817.

Duran-McKinster C, Rodriguez-Jurado R, Ridaura C, de la Luz OrozcoCovarrubias M, Tamayo L, Ruiz-Maldonando R (1999) Elejalde syndrome-a melanolysosomal neurocutaneous syndrome: clinical and morphological findings in 7 patients. Arch Dermatol 135:182-186.

El-Husseini AE, Vincent SR (1999) Cloning and characterization of a novel RING finger protein that interacts with class $\mathrm{V}$ myosins. J Biol Chem 274:19771-19777.
Espreafico EM, Cheney RE, Matteoli M, Nascimento AA, De Camilli PV, Larson RE, Mooseker MS (1992) Primary structure and cellular localization of chicken brain myosin-V (p190), an unconventional myosin with calmodulin light chains. J Cell Biol 119:1541-1557.

Evans L, Hammer J, Bridgman P (1997) Subcellular localization of myosin $\mathrm{V}$ in nerve growth cones and outgrowth from dilute-lethal neurons. J Cell Sci 110:439-449.

Ewart M, Clarke M, Kane S, Chamberlain L, Gould G (2005) Evidence for a role of the exocyst in insulin-stimulated Glut4 trafficking in 3T3-L1 adipocytes. J Biol Chem 280:3812-3816.

Fox MA, Afshari FS, Alexander JK, Colello RJ, Fuss B (2006) Growth conelike sensorimotor structures are characteristic features of postmigratory, premyelinating oligodendrocytes. Glia 53:563-566.

Fritzius T, Frey A, Schweneker M, Mayer D, Moelling K (2007) WD-repeatpropeller-FYVE protein, ProF, binds VAMP2 and protein kinase Czeta. FEBS J 274:1552-1566.

Hardy R, Friedrich VJ (1996) Progressive remodeling of the oligodendrocyte process arbor during myelinogenesis. Dev Neurosci 18:243-254.

Harms K, Craig A (2005) Synapse composition and organization following chronic activity blockade in cultured hippocampal neurons. J Comp Neurol 490:72-84.

Huang JD, Mermall V, Strobel MC, Russell LB, Mooseker MS, Copeland NG, Jenkins NA (1998) Molecular genetic dissection of mouse unconventional myosin-VA: tail region mutations. Genetics 148:1963-1972.

Ivanovich J, Mallory S, Storer T, Ciske D, Hing A (2001) 12-year-old male with Elejalde syndrome (neuroectodermal melanolysosomal disease). Am J Med Genet 98:313-316.

Kachar B, Behar T, Dubois-Dalcq M (1986) Cell shape and motility of oligodendrocytes cultured without neurons. Cell Tissue Res 244:27-38.

Kelton D, Rauch H (1962) Myelination and myelin degeneration in the central nervous system of Dilute-lethal mice. Exp Neurol 6:252-262.

Kim HJ, DiBernardo AB, Sloane JA, Rasband MN, Solomon D, Kosaras B, Kwak SP, Vartanian TK (2006) WAVE1 is required for oligodendrocyte morphogenesis and normal CNS myelination. J Neurosci 26:5849-5859.

Kimura K, Mizoguchi A, Ide C (2003) Regulation of growth cone extension by SNARE proteins. J Histochem Cytochem 51:429-433.

Madison D, Krueger W, Cheng D, Trapp B, Pfeiffer S (1999) SNARE complex proteins, including the cognate pair VAMP-2 and syntaxin- 4 , are expressed in cultured oligodendrocytes. J Neurochem 72:988-998. 
Matesic L, Yip R, Reuss A, Swing D, O’Sullivan T, Fletcher C, Copeland N, Jenkins N (2001) Mutations in Mlph, encoding a member of the Rab effector family, cause the melanosome transport defects observed in leaden mice. Proc Natl Acad Sci USA 98:10238-10243.

Mercer J, Seperack P, Strobel M, Copeland N, Jenkins N (1991) Novel myosin heavy chain encoded by murine dilute coat colour locus. Nature 349:709-713.

Miyata M, Finch E, Khiroug L, Hashimoto K, Hayasaka S, Oda S, Inouye M, Takagishi Y, Augustine G, Kano M (2000) Local calcium release in dendritic spines required for long-term synaptic depression. Neuron 28:233-244.

Noguchi T, Sugisaki T, Tsukada Y (1983) Poor myelination in the central nervous system of "dilute-lethal mutant mice" (d1/d1). Exp Neurol 79:278-282.

Oh E, Thurmond D (2006) The stimulus-induced tyrosine phosphorylation of Munc18c facilitates vesicle exocytosis. J Biol Chem 281:17624-17634.

Ohyama A, Komiya Y, Igarashi M (2001) Globular tail of myosin-V is bound to vamp/synaptobrevin. Biochem Biophys Res Commun 280:988-991.

Pastural E, Barrat FJ, Dufourcq Lagelouse R, Certain S, Sanal O, Jabado N, Seger R, Griscelli C, Fischer A, de Saint Basile G (1997) Griscelli disease maps to chromosome $15 \mathrm{q} 21$ and is associated with mutations in the myosin-Va gene. Nat Genet 16:289-292.

Prekeris R, Terrian DM (1997) Brain myosin V is a synaptic vesicleassociated motor protein: evidence for a $\mathrm{Ca}^{2+}$-dependent interaction with the synaptobrevin-synaptophysin complex. J Cell Biol 137:1589-1601.

Raine C (1997) Oligodendrocytes and central nervous system myelin. In: Textbook of neuropathology, Ed 3 (Davis R, Robertson D, eds), pp 137 164. Baltimore: Williams and Wilkins.

Roach A, Boylan K, Horvath S, Prusiner S, Hood L (1983) Characterization of cloned cDNA representing rat myelin basic protein: absence of expression in brain of shiverer mutant mice. Cell 34:799-806.

Rodriguez OC, Cheney RE (2002) Human myosin-Vc is a novel class V myosin expressed in epithelial cells. J Cell Sci 115:991-1004.

Rosenbluth J, Guo D, Liu Z, Liang W, Schiff R (1994) Effects of cerebellar lesions on tonic seizures, tremor and lifespan in myelin-deficient rats. Brain Res 650:85-92.

Sakisaka T, Baba T, Tanaka S, Izumi G, Yasumi M, Takai Y (2004) Regulation of SNAREs by tomosyn and ROCK: implication in extension and retraction of neurites. J Cell Biol 166:17-25.

Sanal O, Ersoy F, Tezcan I, Metin A, Yel L, Menasche G, Gurgey A, Berkel I, de Saint Basile G (2002) Griscelli disease: genotype-phenotype correlation in an array of clinical heterogeneity. J Clin Immunol 22:237-243.

Schnell E, Nicoll RA (2001) Hippocampal synaptic transmission and plasticity are preserved in myosin $\mathrm{Va}$ mutant mice. J Neurophysiol 85:1498-1501.
Singh BB, Lockwich TP, Bandyopadhyay BC, Liu X, Bollimuntha S, Brazer SC, Combs C, Das S, Leenders AG, Sheng ZH, Knepper MA, Ambudkar SV, Ambudkar IS (2004) VAMP2-dependent exocytosis regulates plasma membrane insertion of TRPC3 channels and contributes to agonist-stimulated $\mathrm{Ca}^{2+}$ influx. Mol Cell 15:635-646.

Song J, Goetz B, Baas P, Duncan I (2001) Cytoskeletal reorganization during the formation of oligodendrocyte processes and branches. Mol Cell Neurosci 17:624-636.

Stachelek SJ, Kowalik TF, Farwell AP, Leonard JL (2000) Myosin V plays an essential role in the thyroid hormone-dependent endocytosis of type II iodothyronine 5' -deiodinase. J Biol Chem 275:31701-31707.

Tilelli CQ, Martins AR, Larson RE, Garcia-Cairasco N (2003) Immunohistochemical localization of myosin Va in the adult rat brain. Neuroscience 121:573-586.

Torok D, Patel N, Jebailey L, Thong F, Randhawa V, Klip A, Rudich A (2004) Insulin but not PDGF relies on actin remodeling and on VAMP2 for GLUT4 translocation in myoblasts. J Cell Sci 117:5447-5455.

Uemura S, Higuchi H, Olivares AO, De La Cruz EM, Ishiwata S (2004) Mechanochemical coupling of two substeps in a single myosin $\mathrm{V}$ motor. Nat Struct Mol Biol 11:877-883.

Wang F, Wolenski J, Cheney R, Mooseker M, Jay D (1996) Function of myosin- $\mathrm{V}$ in filopodial extension of neuronal growth cones. Science 273:660-663.

Wilson R, Brophy P (1989) Role for the oligodendrocyte cytoskeleton in myelination. J Neurosci Res 22:439-448.

Wilson S, Yip R, Swing D, O’Sullivan T, Zhang Y, Novak E, Swank R, Russell L, Copeland N, Jenkins N (2000) A mutation in Rab27a causes the vesicle transport defects observed in ashen mice. Proc Natl Acad Sci USA 97:7933-7938.

Winterbourn C, Woolf F, Woolf L (1971) Brain lipids of mice homozygous for the gene "dilute lethal" (d). J Neurochem 18:1077-1086.

Wu XS, Rao K, Zhang H, Wang F, Sellers JR, Matesic LE, Copeland NG, Jenkins NA, Hammer JA (2002) Identification of an organelle receptor for myosin-Va. Nat Cell Biol 4:271-278.

Yoshida T, Mishina M (2005) Distinct roles of calcineurin-nuclear factor of activated T-cells and protein kinase A-cAMP response element-binding protein signaling in presynaptic differentiation. J Neurosci 25:3067-3079.

Yoshimura A, Fujii R, Watanabe Y, Okabe S, Fukui K, Takumi T (2006) Myosin-Va facilitates the accumulation of mRNA/protein complex in dendritic spines. Curr Biol 16:2345-2351.

Zhou Q, Xiao J, Liu Y (2000) Participation of syntaxin 1A in membrane trafficking involving neurite elongation and membrane expansion. J Neurosci Res 61:321-328.

Zhu D, Tan K, Zhang X, Sun A, Sun G, Lee J (2005) Hydrogen peroxide alters membrane and cytoskeleton properties and increases intercellular connections in astrocytes. J Cell Sci 118:3695-3703. 